\title{
WORKPLACE BULLYING AS A PREDICTOR OF TURNOVER INTENTION AMONG TEACHERS: ROLE OF JOB EMBEDDEDNESS
}

\author{
${ }^{1}$ Samrah Jamshaid, ${ }^{2}$ Dr Najma Iqbal Malik, ${ }^{3}$ Shahida Perveen \\ ${ }^{1} \mathrm{PhD}$ Candidate, Northeast Normal University Jilin, China \\ ${ }^{2}$ Associate Professor, Department of Psychology, University of Sargodha, Pakistan \\ ${ }^{3} \mathrm{PhD}$ Candidate, Department of Psychology, University of Sargodha, Pakistan
}

\begin{abstract}
The current research aimed to investigate workplace bullying, turnover intention and job embeddedness among teachers of colleges and universities of Sargodha, Pakistan. The purposive sampling technique was used for the collection of data. Negative Act Questionnaire (Einarsen, 2001), Turnover Intention Scale (Mitchell, 2001) and Job Embeddedness Scale (Crossley et al, 2007) scales were used to measure the constructs of study. Correlation analysis discovered that workplace bullying has a positive relationship with turnover intentions, which distingue that teachers who faced bullying in the organization have more intention to quit their job. Linear Regression analysis showed a significant impact of bullying on the turnover intention. Hierarchal Regression analysis showed that job embeddedness has significant moderating role between bullying and turnover intention. The current study have some recommendations and conclusion for coming researchers who will be interested to explore the level of teacher's embeddedness who were facing bullying.
\end{abstract}

Keywords: Workplace bullying; Turnover intention; Job embeddedness.

Article Received: 18 October 2020, Revised: 3 November 2020, Accepted: 24 December 2020

\section{Introduction}

The educational institute aimed to provide a healthy educational environment for students. They along with parents, being major socialization agents played significant roles in the psychosocial development of students. In this whole process of socialization, the teacher served as a vital agent to impart sound development in students. However, the role played by teacher heavily depends upon his/her commitment, dedication, and embeddedness with the educational institute. The presence of a conducive work environment and absence of organizational politics or negative stressors in educational institutes are of prime importance to sustain teachers' dedication for his/her job (Yildiz, 2018). A negative work environment such as bullying can affect teachers teaching patterns that will ultimately affect student's performance.

Staff turnover is necessary to know because high turnover can, directly and indirectly, impact organization, due to the increased cost of recruiting and training, loss of productive opportunities, reduced income, and generally reduced morale of employees (Hayward, Bungay, Wolff, \& MacDonald, 2016; Lu \& Gursoy, 2016;
Long et al., 2016; Abid \& Butt, 2017; Paras1z et al., 2017; Labrague et al., 2018), depending on the level of the work left unoccupied, overall employee turnover costs will cost employers more than 100 per cent of the annual compensation or salary of a single employee (Upadhayay \& Vrat, 2016). Exposure to workplace bullying is one of the factors that can intensify the turnover purpose of valued employees (Dyk, 2016).

Moreover, being a part of an educational institute, teachers' embeddedness with their institutes mainly is based upon the good environment as well as the level of bullying, as if they face bullying they will consequently develop intentions to leave institutes. Likewise, a bullying-free environment will also buffer the job embeddedness among teachers but if not so they will ultimately develop turnover intentions for their job. Similarly, higher bullying that results in high job turnover in any institute will not only damages the conducive learning environment but also impart great financial loss to educational institutes i.e., if the teacher left institutes and go for another organization (brain drain), it will be a loss of teaching sectors and to recruits, new employees will not only be costly yet 
administration will also not be assured about getting good and trained employees again (Dos Santos, 2020). Moreover, training a teacher takes time and it's not an easy task to be achieved overnight. Furthermore, it also negatively impacts institutional reputation that will consequently affect the new employees' intake and commitment development ((Bhatti, Bhatti, Akram, Bilal, \& Akram, 2016). Furthermore, the study has explored that in industrial organizations of Jordan level of person-related bullying is medium but the work-related bullying is high, however, workplace bullying causes $6.7 \%$ of employees to leave the organization and to develop turnover intentions (Al-Jawazneh \& Smadi, 2017).

The intention of employee turnover provides an alternative to existing employee turnover. How to manage the changing job environment is one of the challenging problems faced by universities today. According to Tandung (2016), the aim of turnover describes the relative strength of the objective or intent of a person to voluntarily withdraw from an organization permanently. It is a motive or goal that causes an employee to abandon his or her current workplace. Turnover is the ratio of the total number of workers leaving an organization at a given time, according to Akhtar, Ghufran, and Fatima (2017), it refers to the average number of employees remaining at the same time in that organization. It is a behaviour that defines the process of leaving an organization or replacing workers. The intention of turnover is linked to elements of an employee; the thinking or feeling of leaving the work, the intention of seeking another job, and the intention of quitting the job (Lee et al., 2017; Lee et al., 2017).

Turnover is based on two categories among which one is voluntary turnover and the other is involuntary turnover. Here voluntary turnover is decided by the individuals of the organization but the organization itself has no role in it. Involuntary turnover is opposite to voluntary because as in this turnover, the organization forced an employee to make the intention to leave the organization. This can happen in days or years depending upon the organizational situations faced by an individual. Mostly unskilled and younger employees have high intention to leave the organization than older and experienced employees; may the reason is maturity and patience with time or can be the high sense of command upon a given task that buffer the later group commitment and citizenship behaviour towards their jobs (Saraih et al., 2017).

Workplace bullying or insulting tends to mean is neglecting and disturbing individual work assignments adversely. Bullying is a tormenting process in which the individual is confronted by the mocking acts in which his/her ego is injured because of orderly harmful social acts (Einarsen \& Mikkelsen, 2003). In several cases, the purpose of turnover can occur either voluntarily where the employee decides willingly to leave the company or unintentionally, replacing an employee for a particular job, mostly without the employee's prior willingness (Williams, \& Owusu -Acheampong, 2016).

Job embeddedness is referred to as how an individual is connected to an organization. In terms of three dimensions, researchers calculate as fit, links, and sacrifice (Choi \& Kim, 2015). Embeddedness relates to fit in the organization as an individual. If an employee is embedded in a job then he/she is fit with the organization by having good complementary, extra development abilities and also will show a good connection with other employees. Though a significant positive relationship between embeddedness and social capital was evident, however, a slight decline in this relationship was also evident over time $(\mathrm{Ng} \&$ Feldman, 2010). Empirical evidence also examined job embeddedness construct as a response towards the turnover model which further explored on the job and off job embeddedness factors that concludes the reasons why employee like to stay in an organization. Results showed that one of the reasons is the work-life quality that has a significant positive effect on job embeddedness (Moses, 2013). However, burnout has a significant negative relationship with employees' turnover intention (Scanlan \& Still, 2019).

\section{Literature Review}

Organizations these days faced many issues among which one prominent is workplace bullying also been found as the leading cause of employee's intentions for leaving an organization to find another good alternative work environment. HR consultants, policymakers, and organizational psychologists found various ways to deal with workplace bullying yet bullying is not easy to deal with phenomena. Previous literature 
suggests that bullying applied to individuals significantly and positively predicts turnover. Compared to teachers who have never been subject to abuse, bullied teachers have more intention of turnover (Anjum, \& Muazzam, 2018). Such serious individual consequences, in turn, have severe organizational results, according to Bernstein and Trimm (2016), as employees subjected to workplace bullying experience decreased job satisfaction and increased turnover intention, which is a form of exclusion from work. Therefore, previous research indicated that exposure to workplace bullying is related to turnover intention (e.g., Bahjat, \& Ziad, 2017; Coetzee \& Oosthuizen, 2017; Coetzee \& van Dyk, 2018; Rosario-Hernández, \& Millán, 2018).

Previous literature examined various factors leading to turnover intention, such as the attitude of the employee, job satisfaction, workplace bullying, management, self-assessment, compensation, commitment, and judgment on decisions (Laureano et al., 2018). Reduced employee turnover can benefit an organization financially and can have a positive social benefit for the community in turn (Skelton, (2017). Previous studies argue that the experience of bullying is likely to make some tender-hearted workers more vulnerable because the perceived breach of psychological contract plays a great role in explaining their turnover intentions, and they feel a deeper connection between exposure to workplace bullying and turnover intentions (Salin's \& Notelaers, 2017).

On the other hand, related job outcomes of bullying in the workplace consist of job dissatisfaction, absenteeism, organizational engagement, actual turnover, and turnover intention (Suifan, 2015). Charilaos et al. (2015) also investigated Australian teachers and founded that workplace bullying is positively related to turnover intention.

Moreover, high workplace bullying also restricts ones' connectedness towards his or her job, satisfaction with job or organization (Paul, \& Kee, 2020); bullied employee feels deceived by the higher authorities as the perception of psychological contract violation is high in case of being bullied at the workplace (Coetzee \& Dyk, 2018). Ultimately this damages his vigour, dedication, and job commitment and results in higher turnover intentions even this trend was found to be evident among highly qualified teachers of Pakistani universities and colleges (Anjum \& Muazzam, 2018; Jamshaid \& Malik, 2018; Israa \& Sunnel, 2018). However, metaanalysis literature also postulated the positive role of job embeddedness in the relationship of bullying and turnover intentions of employees as job embeddedness strongly predicts actual turnover, intention to leave, job satisfaction, and organizational commitment (Treuren \& Fein, 2018).

Keeping in view the significance of the construct under study present research is unique to explore the phenomena mainly among teachers of higher educational institutes. Previously the variables have been studied in the organizational culture of Pakistan (Kousar, 2018; Riasat, \& Nisar, 2016; Ahmad, Khattak, \& Ahmad, 2016; Ali, Asad, \& Yousaf, 2019; Najam, Ishaque, Shoukat, Hayat Awan, \& Ansari, 2018) but the uniqueness of present study lies into explores these variables in teaching institutes.

Objectives. The present research aimed to explore the relationship of workplace bullying with turnover intention and to explore the role of workplace bullying on turnover intention. Another objective was to find out the role of embeddedness in the relationship between workplace bullying and turnover intention among teachers.

Hypotheses. It hypothesized that workplace bullying would be the positive predictor of teacher's turnover intention. It was also hypothesized that job embeddedness would have a significant moderating role in the relationship of bullying with turnover intention among teachers.

\section{Methods}

Sample. A purposive sample of 223 teachers was collected from different private and public colleges and universities of Sargodha, Pakistan. Inclusion criteria were set as only those teachers with the educational level of post-graduation and Doctorate, with at least more than two years of job experience were made part of the study. They all were teaching graduate and postgraduate classes and were actively involved in research activities. Both male $47 \%$ and female $53 \%$ of teachers were part of the study. Sample age range was 26 to 58 
years $(\mathrm{M}=31.45, \mathrm{SD}=5.65)$ and the experience was from 3 to 26 years $(\mathrm{M}=16.25, \mathrm{SD}=4.35)$. Only regular/permanent job holders were made part of the study and those who were visiting, contractual or had less than two years of job experiences were excluded from the study.

\section{Assessment measures}

Demographic data form was designed according to the purpose of study which contains questions related to the respondent's gender, age, marital status, professional affiliation, qualification, job experience, and monthly salary.

Negative Acts Questionnaire is constructed by Einarsen (2001) was used to measure bullying faced by employees in the organization. As per scale criteria, employees who were facing bullying from six months were the part of the study. The scale has 22 items with 5 points Likert type response format ranges from $(1=$ never to, $5=$ daily $)$. Cronbach's alpha in the current study is found as 0.66 .

Turnover Intention Scale developed by Mitchell, (2001) was used to measure employee's turnover intentions. The scale has only 3 items with 5 points Likert type response format here 1 stand for "Strongly disagree" to 5 which stand for "Strongly agree". The Cronbach's alpha for this scale in the present study was 0.96 .

Job Embeddedness Scale developed Crossley et al. in 2007. This scale consisted of 40 items divided into six sub-scales i.e., community fit, organization fit community links, organization links, community sacrifice and organization sacrifice. Response format of this scale was 5 point Likert type ranging from $1=$ "strongly disagree" to $5=$ "strongly agree". Reliabilities for this measure in the present research are i.e. job embeddedness scale $\alpha=0.91$, community

Table 1. Mean, standard deviation, Alpha reliability and Correlation analysis of workplace bullying with turnover intention $(N=223)$

\begin{tabular}{|c|l|c|c|c|c|c|c|c|c|c|c|c|c|}
\hline & Variables & $\alpha$ & $M$ & $S D$ & 1 & 2 & 3 & 4 & 5 & 6 & 7 & 8 & 9 \\
\hline 1 & WB & .66 & 58.92 & 20.49 & - & $.26^{*}$ & -.01 & .01 & -.14 & .06 & .00 & -.06 & -.00 \\
\hline 2 & TOI & .96 & 9.66 & 2.20 & & - & -.16 & .11 & -.17 & -.07 & $-.21^{*}$ & -.08 & -.12 \\
\hline 3 & JE & .91 & 141.89 & 16.15 & & & - & .19 & $.22^{*}$ & $.71^{* *}$ & $.84^{* *}$ & $.71^{* *}$ & $.87^{* *}$ \\
\hline 4 & CL & .72 & 17.94 & 1.58 & & & & - & $.32^{* *}$ & .05 & .08 & .06 & .03 \\
\hline 5 & OL & .88 & 21.51 & 1.63 & & & & & - & .02 & .05 & .13 & .09 \\
\hline 6 & CF & .72 & 18.94 & 3.45 & & & & & & - & $.53^{* *}$ & $.46^{* *}$ & $.49^{* *}$ \\
\hline 7 & OF & .85 & 34.90 & 6.01 & & & & & & & - & $.50^{* *}$ & $.61^{* *}$ \\
\hline 8 & CS & .61 & 11.58 & 2.29 & & & & & & & & - & $.57^{* *}$ \\
\hline 9 & OS & .85 & 37.01 & 7.22 & & & & & & & & \\
\hline
\end{tabular}

fit $\alpha=0.72$, organization fit $\alpha=0.85$, community links $\alpha=0.72$, organization links $\alpha=0.88$, community sacrifice $\alpha=0.61$, and organization sacrifice $\alpha=0.85$.

\section{Procedure}

The research was carried out by the formal approval of departmental ethical research committee followed by formal approval of the Board of Studies in Psychology, University of Sargodha, Pakistan. Current study strictly adhered ethical protocol of scientific research and proper permission from authors to use scales followed by permission of data collection from concerned colleges and universities were sought. A purposive sample of teachers was contacted at their workplace and was elucidated about the objective and purpose of the study. Formal informed consent for voluntary participation was obtained and confidentiality about collected data was assured. Furthermore, they were provided proper instructions about scales and were requested to provide data with honest responses by leaving no question unanswered. Total 247 questionnaire booklets were distributed and after data cleaning only 223 questionnaire booklets were finalized for data analysis as rest were discarded due to incompleteness or random response problems. The data collection period was from December 2019 to May 2020. After data, cleaning processes finished questionnaires were secure and unprocessed data was recorded and transported to an SPSS data set.

\section{Results}

Collected data of sample $(N=223)$ was analyzed by SPSS $23^{\text {rd }}$ version. Descriptive statistics, Pearson correlation, multiple and hierarchal regression analyses were computed to test hypotheses. 
Note. $\mathrm{WB}=$ workplace bullying; $\mathrm{TOI}=$ turnover intention; $\mathrm{JE}=$ job embeddedness; $\mathrm{CL}=$ community link; $\mathrm{OL}=$ organization link; $\mathrm{CF}=$ community fit; $\mathrm{OF}=$ organization fit; $\mathrm{CS}=$ community sacrifice; $\mathrm{OS}=$ organization sacrifice.

$* p>.05, * * p>.01$.

The table shows mean, standard deviation, alpha reliability and correlation among study variables. Alpha reliability for all variables ranges from .61 to .96 which indicates good internal consistency in scales. Furthermore, the result shows that workplace bullying is significantly positively correlated with turnover intention $(r=.26, p<.05)$ hence, it might be inferred that workplace

\begin{tabular}{llll} 
Predictor & $\beta$ & $R^{2}$ & $F($ Model) \\
\hline Workplace bullying & $.26^{*}$ & .07 & 6.66
\end{tabular}

${ }^{*} p>.05$.

Regression analysis shows workplace bullying like predictor for turnover intention. The value of $R^{2}$ (.07) indicated that $7 \%$ independent variable variance can be accounted, through the predictor $[F(1,222)=6.66]$. The finding indicates that

bullying has a positive relationship with turnover intention. Results also indicate that turnover intention has a significant negative relationship with organization fit $(r=-.21, p<.05)$

Table 2. Simple linear Regression Analysis for workplace bullying predicting turnover intention among Teachers $(N=223)$

bullying is founded to be a significant predictor for turnover intention.

Table 3. The moderating role of embeddedness with the relationship between bullying and Turnover Intention $(N=223)$

$* p>.05$.

\begin{tabular}{llrr}
\hline Models & $\Delta R^{2}$ & $\beta$ & $F$ \\
\hline Model 1 & .07 & $.26^{*}$ & 6.66 \\
(WB) & & & \\
Model 2 & .98 & $.26^{*}$ & 4.73 \\
(WB) (JE) & & -.17 & \\
Model 3 & .12 & $.31^{*}$ & 3.78 \\
(WB) (JE) & & -.13 & \\
(WB)x(JE) & & -.15 & \\
Total R & & & \\
\hline
\end{tabular}

Table 3 demonstrates the moderating role of Job embeddedness (JE) in relationship with workplace bullying (WB) and turnover intention. Model 1 founded to be significant $\left\{\Delta R^{2}=.07, f(1,222)=\right.$ $6.66, p<.01\}$ like workplace bullying is causative $7 \%$ variance in turnover intention $\left(R^{2}=.07 \quad .002, \beta\right.$ $=.26$ ). Model 2 also founded to be a significant $\left\{\Delta R^{2}=.98, f(1,221)=4.73, p<.01\right\}$ and job

embeddedness is causative $98 \%$ variance in turnover intention $\left(R^{2}=.98, .002, \beta=.26\right)$. However, model 3 founded to be non-significant $\left\{\Delta R^{2}=.12, f(1,220)=3.78, \mathrm{p}>.05\right\}$ interface of workplace bullying and job embeddedness are causative $12 \%$ variance in turnover intention $\left(R^{2}=\right.$ $.12 .06, \beta=.31)$. 


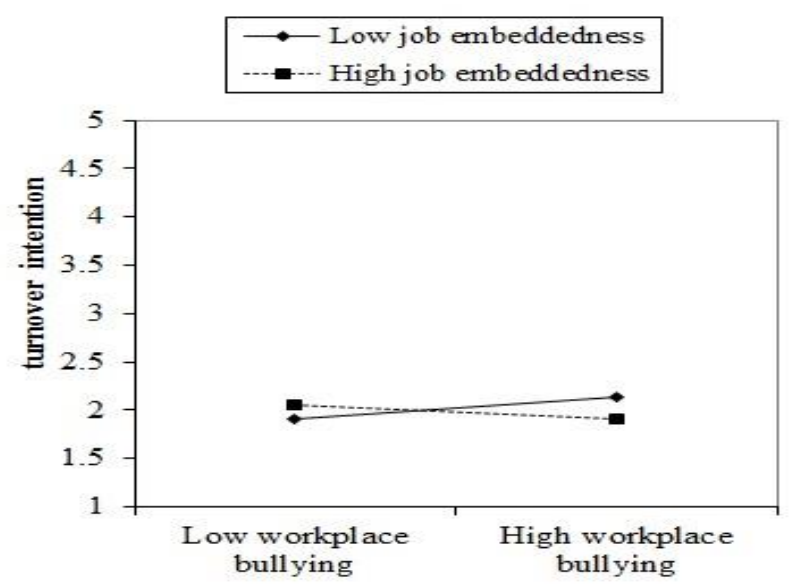

Figure 1: Moderating role of job embeddedness in relationship between workplace bullying and turnover intention.

\section{Discussions}

This study attempted to examine the relationship of workplace bullying with turnover intention. One of the other main objectives was to explore the moderating role of job embeddedness with bullying and turnover intention. Generally, tests of all hypotheses yield significant insights keen on the relative value of different background of bullying and turnover. The study hypothesis that workplace bullying would be the positive predictor of teacher's turnover intention was accepted as significant results revealed that bullying has a strong significant and negaitive impact on turnover intention. Findings are also consistent with the study of Anjum and Muazzam (2018) who found that bullying positively and significantly predicted turnover intention among teachers and bullied teachers showed significantly high intentions to leave their jobs as compared to teachers who never faced bullying. On a similar note, empirical evidence concluded that bullying increases the risk of losing talented and qualified employees as due to consistent pressures of negative work environment pushed far behind other and ultimately decides to quit their job (Paul, \& Kee, 2020) or leave a job over and over again. Findings of the current study also confirmed the earlier findings of Salin and Notelaers (2017), that highly benevolent employees are more affected by exposure to bullying behaviour, although the effects were equally detrimental, irrespective of benevolent behaviour when employees were exposed to very high levels of bullying. Furthermore, in research by Coetzee and Dyk (2018), it was concluded that perceptions of work- and person-related bullying were linked to low levels of vigour and dedication which in turn were associated with high turnover intention. Moreover, the relationship between exposure to bullying and turnover intention is also partially explainable by the concept of employee's perceived psychological contract violation. Previous studies demonstrated that Job stress is also mediating the relationship between turnover intention and workplace ostracism (Riasat, \& Nisar, 2016).

This study also hypothesizes that job embeddedness would have a significant moderating role in the relationship of bullying with turnover intention among teachers. The results determined the non-significant moderating role, which showed that job embeddedness has no moderating role in the relationship between bullying and turnover intention. Previous studies demonstrated that Job satisfaction negatively linked to turnover intentions, and when off-the-job embeddedness increased, this negative link was greater (vs. low). Job stress was linked positively to turnover intentions, but this relationship was buffered by high (vs. low) off-the-job embeddedness. Conversely, the association between work stress and turnover intentions was much stronger when on-the-job embeddedness was higher (vs. low) (Fasbender, Van der Heijden, \& Grimshaw, 2019).

Berthelsen (2011) in the study has postulated that employees who faced bullying at times still like or continue to work in that organization due to multiple reasons e.g., non-availability of other jobs or incentives they are getting in the current organization is more as compared to other options or maybe they are in dire need of this current job. 
However, another recent study investigated the role of job embeddedness and concluded that it decreases the level of work and life conflict which lead them to leave the organization (Treuren \& Fein, 2018).

\section{Conclusion}

The present study concluded that workplace bullying was a strong and positive predictor of turnover intention among teachers. This study also concluded that there was no moderating role of job embeddedness in the relationship between workplace bullying and turnover intention of teachers.

\section{Limitations and Future Studies}

Like every other social science research current study also had some limitations. The first limitation was the use of a purposive sample that may cause a non-homogeneous factor in sampling so it is better to use a random sampling technique to make data skewed. Another limitation was the collection of data from only one city of Pakistan which limited the generalizability of results to the overall population of Pakistan so future researchers should collect data from multiple cities of Pakistan. Moreover, the use of selfexplanatory questionnaires and data collection from designated workplaces might be served as a limitation as this may restrict them to respond freely and cause the faking good response incidences. Therefore, it is recommended that future research may opt qualitative measures to get an in-depth understanding of the phenomena and data must also be collected on other than their workplaces to ensure true responses.

\section{Practical Implications}

This study might be helpful for the administration of higher education institutes to focus on the job embeddedness of their employees and safe them from bullying to decrease the level of turnover intention from their organization. However, it can also be helpful to facilitate the employees to increase their level of embeddedness toward their job. Furthermore, findings of this study could also be useful in Human resource management, organizational psychology and social psychology.

\section{References}

1. Abid, G., \& Butt, T. (2017). Expressed turnover intention: Alternate method for knowing turnover intention and eradicating common method bias. International Letters of Social and Humanistic Sciences, 78.

2. Ahmad, W., Khattak, A. J., \& Ahmad, G. (2016). Impact of abusive supervision on job satisfaction and turnover intention: Role of power distance as a moderator. City University Research Journal, 6(1), 122-136.

3. Akhtar, M. W., Ghufran, H., \& Fatima, T. (2017). The effect of emotional intelligence on turnover intentions; The role of employee well-being, engagement and perceived organisational support. Jinnah Business Review, 5(2), 69-80.

4. Ali, H. G., Asad, M., \& Yousaf, M. (2019). Supervisor Incivility and Turnover Intentions with the Mediating Role of Job Burnout and Moderation of Job Performance. NUML International Journal of Business \& Management, 14(1), 89-101.

5. Aljawazneh, B., \& Ziad, S. (2017). Workplace bullying as a predictor of intention to leave among workers at the industrial organizations in Jordan. International Research in Economics and Management Sciences, 6(1), 15-39.

6. Anjum, A., \& Muazzam, A. (2018). Workplace bullying and turnover intention among university teachers. Journal of Arts and Social Sciences, 2, 51-62.

7. Bernstein, C., \& Trimm, L. (2016). The impact of workplace bullying on individual wellbeing: The moderating role of coping. SA Journal of Human Resource Management, 14(1), 12.

8. Berthelsen, M., Skogstad, A., Lau, B., \& Einarsen, S. (2011). Do they stay or do they go? A longitudinal study of intentions to leave and exclusion from working life among targets of workplace bullying. International Journal of Manpower, 32 (2), 178-193

9. Bhatti, M. H., Bhatti, M. H., Akram, U., Bilal, M., \& Akram, Z. (2016). Impact of organization commitment on turnover intention: Mediating role of job 
contentment. European Journal of Business and Management, 8(13), 24-39.

10. Charilaos, K., Michael, G., Chryssa, B. T., Panagiota, D., George, C. P., \& Christina, D. (2015). Validation of the Negative Acts Questionnaire (NAQ) in a sample of Greek teachers. Psychology, 6(01), 63.

11. Choi, J. S., \& Kim, K. M. (2015). Job embeddedness factors as a predictor of turnover intention among infection control nurses in Korea. American Journal of Infection Control, 43(11), 1213-1217.

12. Coetzee, M., \& Oosthuizen, R. M. (2017). Work-role psychosocial flourishing: Its mediation role on workplace bullying and employee turnover intention. Journal of Psychology in Africa, 27(3), 211-215.

13. Coetzee, M., \& van Dyk, J. (2018). Workplace bullying and turnover intention: Exploring work engagement as a potential mediator. Psychological Reports, 121(2), 375-392.

14. Crossley, C. D., Bennett, R. J., Jex, S. M., \& Burnfield, J. L. (2007). Development of a global measure of job embeddedness and integration into a traditional model of voluntary turnover. Journal of Applied Psychology, 92(4), 1031.

15. Dos Santos, L. M. (2020). Stress, burnout, and turnover issues of Black expatriate education professionals in South Korea: Social biases, discrimination, and workplace bullying. International Journal of Environmental Research and Public Health, 17(11), 3851.

16. Einarsen, S. (2001). The Negative Acts Questionnaire: Development, validation and revision of a measure of bullying at work. In Proceedings of the 10th European Congress on Work and Organisational Psychology, Prague, May 2001.

17. Einarsen, S., Hoel, H., \& Cooper, C. (Eds.). (2002). Bullying and emotional abuse in the workplace: International perspectives in research and practice. CRC press.

18. Fasbender, U., Van der Heijden, B. I., \& Grimshaw, S. (2019). Job satisfaction, job stress and nurses' turnover intentions: The moderating roles of on-the-job and off-the-job embeddedness. Journal of Advanced Nursing, 75(2), 327-337.

19. Hayward, D., Bungay, V., Wolff, A. C., \& MacDonald, V. (2016). A qualitative study of experienced nurses' voluntary turnover: learning from their perspectives. Journal of Clinical Nursing, 25(9-10), 1336-1345.

20. Israa, S., \& Suneel, I. (2018). Relationship between Workplace Bullying, Resilience and Job Satisfaction among Employees in a University in Pakistan. International Journal of Social Sciences \& Educational Studies, 5(2), 42.

21. Jamshaid, S., \& Malik, N. I. (2018). Job Embeddedness related to Organizational Justice: Role of Workplace Bullying among Higher Education Institutes. Foundation University Journal of Psychology, 2(2), 39-68.

22. Kousar, S. (2018). Examining Turnover Intentions as the Outcomes of Workplace Bullying Testing a Mediated and Moderated Model (Doctoral dissertation, CAPITAL UNIVERSITY).

23. Labrague, L. J., Gloe, D., McEnroe, D. M., Konstantinos, K., \& Colet, P. (2018). Factors influencing turnover intention among registered nurses in Samar Philippines. Applied Nursing Research, 39, 200-206.

24. Laureano, R. M., Fernandes, A. L., Hassamo, S., \& Alturas, B. (2018). Facebook satisfaction and its impacts on fundraising: a case study at a Portuguese non-profit organization. Journal of Information Systems Engineering and Management, 3(1), 04.

25. Lee, C. H., Wang, M. L., \& Liu, M. S. (2017). When and how does psychological voice climate influence individual change readiness? The Mediating Role of Normative Commitment and the Moderating Role of Work Engagement. Frontiers in psychology, 8, 1737.

26. Lee, T. W., Hom, P. W., Eberly, M. B., Junchao (Jason) Li, \& Mitchell, T. R. (2017). On the next decade of research in voluntary employee turnover. Academy of Management Perspectives, 31(3), 201-221.

27. Long, S. (2016). An analysis on the relationship between work-family conflict 
and turnover intention: A case study in a manufacturing company in Malaysia. International Business Management, 10(3), 176-182.

28. Lu, A. C. C., \& Gursoy, D. (2016). Impact of job burnout on satisfaction and turnover intention: do generational differences matter?. Journal of Hospitality \& Tourism Research, 40(2), 210-235.

29. Mitchell, T. R. (2001). The unfolding model of voluntary turnover and job embeddedness: Backgrounds for a comprehensive theory of attachment. Research in Organisational Behaviour, 23, 189-246.

30. Moses, A. R. (2013). Understanding the relationship of job embeddedness with social and human capital: The importance of organizational identification. (Doctoral dissertation, The University of Texas at Arlington).

31. Najam, U., Ishaque, S., Shoukat, S., Hayat Awan, M., \& Ansari, N. Y. (2018). Interactive effect of CCM between the relationship of workplace bullying, burnout, and turnover intentions. Cogent Business \& Management, 5(1), 1422233.

32. Ng, M. L. \& Feldman, B. K. (2010). The effect of embeddedness on behaviours related innovation. Journal of Behavioural Sciences 49(6), 1067-1087.

33. Parasız, Ö., Koç, M., Ilgar, E., \& Şahin, M. Y. (2017). Relationship between organizational commitment and turnover intentions of academics. Journal of Human Sciences, 14(4), 4065-4076.

34. Paul, G. D., \& Kee, D. M. H. (2020). HR, Workplace Bullying, and Turnover Intention: The role of Work Engagement. Journal of Environmental Treatment Techniques, 8(1), 23-27.

35. Riasat, F., \& Nisar, Q. A. (2016). Does a workplace incivility influence employee's job stress and turnover intentions by moderating role of psychological capital: Descriptive study on banking sector Gujranwala; Pakistan. International Journal of Scientific and Engineering Research, 7(12), 17-30.

36. Rosario-Hernández, E., \& Millán, L. V. R. (2018). Effect of the exposure to workplace bullying on turnover intention and the mediating role of job satisfaction, work engagement, and burnout. Revista Interamericana de Psicología Ocupacional, 37(1), 26-51.

37. Salin, D., \& Notelaers, G. (2017). The effect of exposure to bullying on turnover intentions: the role of perceived psychological contract violation and benevolent behaviour. Work \& Stress, 31(4), 355-374.

38. Saraih, U. N., Aris, A. Z. Z., Karim, K. M., Samah, I. H. A., Sa'aban, S., \& Mutalib, S. A. (2017). Relationships between organizational commitment, $\mathrm{OCB}$, organizational justice and turnover intention: Evidence from educational institution in Malaysia. Review of Integrative Business and Economics Research, 6(2), 64.

39. Scanlan, J. N., \& Still, M. (2019). Relationships between burnout, turnover intention, job satisfaction, job demands and job resources for mental health personnel in an Australian mental health service. BMC Health Services Research, 19(1), 62.

40. Skelton, A. R. (2017). Job satisfaction and job embeddedness as predictors of manufacturing employee turnover intentions.

https://scholarworks.waldenu.edu/dissertat ions/4176/.

41. Suifan, T. S. (2015). The effect of human resources practices on organizational commitment: A Jordanian study. Journal of Management Research, 7(4), 222-232.

42. Tandung, J. C. (2016). The link between HR attributions and employees' turnover intentions. Gadjah Mada International Journal of Business, 18(1), 55-69.

43. Treuren, G. J., \& Fein, E. C. (2018). Offthe-job embeddedness as a moderator of the relationship between work and life conflict and turnover intention. The International Journal of Human Resource Management, 1-22.

44. Upadhayay, L., \& Vrat, P. (2016). Analysis of impact of industry-academia interaction on quality of technical education: A system dynamics approach. 
Computers \& Industrial Engineering, 101, 313-324.

45. Van Dyk, J. (2016). The meditating effect of a psychological wellbeing profile in the bullying and turnover intention relation. Unpublished doctoral thesis, University of South Africa, Pretoria, South Africa.

46. Williams, A. A., \& Owusu-Acheampong, E. (2016). Human resource management practices and their effect on employee turnover in the hotel industry in Cape Coast, Ghana. Global Journal of Human Resource Management, 4(4), 35-45.

47. Yildiz, K. (2018). The Relationship between Teachers' Job Embeddedness and Vocational Belonging Perceptions. Universal Journal of Educational Research, 6(7), 1454-1466. 